The reason for the patient's persistent vomiting in the first five months of life may well have been a slower development of his antireflux mechanism, but we have not been able to confirm this hypothesis.

\footnotetext{
References

${ }^{1}$ O'Brien D, Rodgerson DO, Ibbott FA. Laboratory manual of pediatric micro- and ultramicro biochemical techniques. 4th ed. New York: Harper \& Row, 1968:231.

2 Schreiner RL, Lemons JA, Gresham EL. A new complication of nutritial management of the low-birth-weight infant. Pediatrics 1979;63:683-4.
}

${ }^{3}$ Menke JA, Stallworth RE, Bindstadt DH, Strano AJ, Wallace SE. Medication bezoar in a neonate. Am J Dis Child 1982;136:72-3.

${ }^{4}$ Metlay LA, Klionsky BC. An unusual gastric bezoar in a newborn: polystyrene resin and candida albicans. $J$ Pediatr 1983;102:121-3.

5 Portuguez-Malavasi A, Aranda JV. Antacid bezoar in a newborn. Pediatrics 1979;63:679 80.

${ }^{6}$ Hewitt GJ, Benham ES. A complication of gaviscon in a neonate-'the gavisconoma'. Aust Paediatr J 1976;12:47-8.

Correspondence to Dr M Sinaasappel, Department of Paediatrics, Gastro-enterological Division, Erasmus University and University Hospital, Rotterdam, The Netherlands.

Received 7 November 1983

\title{
Intrahepatic cysts in biliary atresia after successful hepatoportoenterostomy
}

\author{
S SAITO, T NISHINA, AND Y TSUCHIDA \\ Department of Paediatric Surgery, University of Tokyo, Japan
}

SUMMARY A patient with an unusual association of biliary atresia and two intrahepatic cysts is reported. The infant was treated by a hepatoportoenterostomy at 2 months of age and by subsequent drainage of the cysts at 13 months. These cysts were detected by ultrasound during a febrile illness.

A boy who had extrahepatic biliary atresia and two solitary intrahepatic cysts was successfully treated by hepatoportoenterostomy and by external drainage of the cysts.

\section{Case report}

A boy, born at term in November 1979, had neonatal hyperbilirubinaemia and underwent phototherapy on the third day of life. Jaundice did not resolve, however, and the infant began to pass acholic stools. On physical examination the sclerae and skin were icteric. Laboratory investigations showed: total protein, $52 \mathrm{~g} / \mathrm{l}$; albumin, $34 \mathrm{~g} / \mathrm{l}$; total bilirubin, $121.4 \mu \mathrm{mol} / 1$ ( $7.1 \mathrm{mg} / \mathrm{dl})$; direct bilirubin, $92.3 \mu \mathrm{mol} / 1(5.4 \mathrm{mg} / \mathrm{dl})$; serum glutamic oxalo-acetic transaminase, $54 \mathrm{IU}$; serum glutamic peruvate transaminase, $37 \mathrm{IU}$; lactate dehydrogenase, 271 IU; alkaline phosphatase, 310 IU.

Laparotomy performed at 56 days of age showed a cystically dilated choledochus and an atrophic gall bladder. An operative cholangiogram showed a cystic choledochus without any communication into the duodenum or intrahepatic bile ducts. The dilated and cord like portions of the extrahepatic bile ducts were totally resected and a hepatoportoenterostomy ${ }^{1}$ was performed, leaving the distal end of the jejunal loop as a complete external fistula ${ }^{2}$ converted to internal drainage three weeks after the initial surgery. Histological examination showed biliary atresia.

The infant did well for the next 6 months, although he did have several transient fevers which were quickly resolved with antibiotics. His serum bilirubin concentration at this time was $15.4 \mu \mathrm{mol} / \mathrm{l}$ $(0.9 \mathrm{mg} / \mathrm{dl})$. At the age of $12 \mathrm{months}$, an abdominal ultrasound examination was performed during an episode of fever. Two cystic spaces, $1.75 \mathrm{~cm} \times 2.5$ $\mathrm{cm}$ on the right and $1.2 \mathrm{~cm} \times 2.0 \mathrm{~cm}$ on the left, were identified within the parenchyma at the porta hepatis. Percutaneous transhepatic cholangiography clearly showed two separate solitary cysts (Fig. 1) which did not communicate with the hepatic ducts, with the hepatojejunal loop, or with each other. The right cyst contained yellowish fluid (total bilirubin, $25.6 \mu \mathrm{mol} / 1(1.5 \mathrm{mg} / \mathrm{dl}))$ and the left one clear fluid (total bilirubin, $1.7 \mu \mathrm{mol} / 1(0 \cdot 1 \mathrm{mg} / \mathrm{dl})$. An ultrasound scan performed two weeks later showed that the cysts had enlarged-the right one to 4.0 $\mathrm{cm} \times 5.0 \mathrm{~cm}$, and the left one to $2.0 \mathrm{~cm} \times 5.0 \mathrm{~cm}$ (Fig. 2).

A third laparotomy was performed in December 1980. The right cyst was located behind the hepatojejunal loop, but dye injected into it failed to show communication with the loop. The cyst walls were opened and Penrose drains to the abdominal wall 


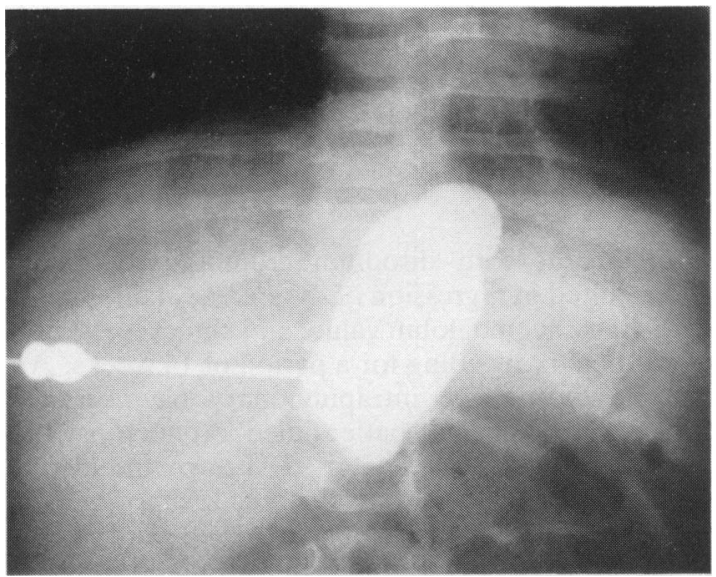

Fig. 1 Percutaneous transhepatic cholangiography at 12 months of age, showing the left cyst.

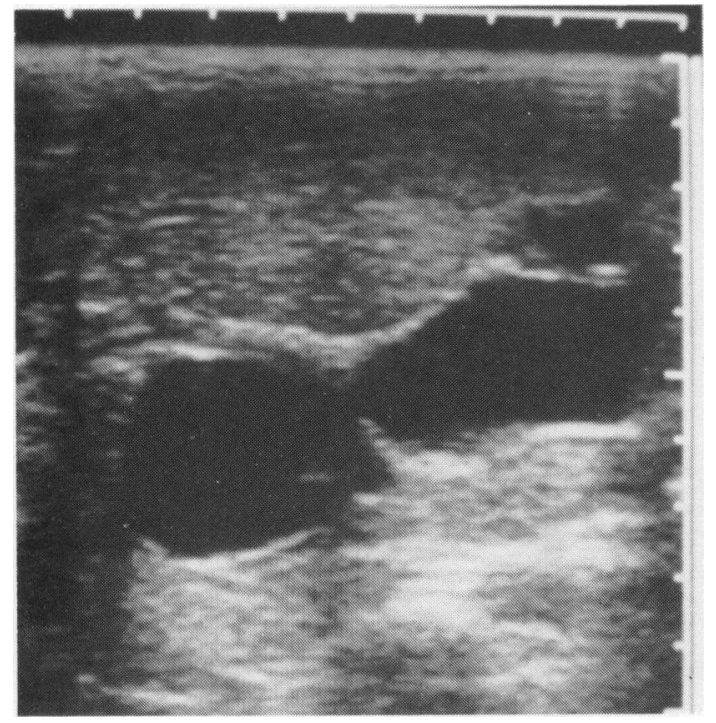

Fig. 2. Ultrasound scan taken one day before the third operation, showing two intrahepatic cysts.

were left in them. Microscopic examination showed that the cyst walls consisted of fibrous tissue, devoid of a lining epithelium.

Postoperative fluid flow from the drainage began to decrease 7 days after operation, and an ultrasound scan performed 28 days later showed that the cysts had decreased in size remarkably. Ultrasound performed three months later showed that the cysts were completely obliterated and the external fistula had also closed spontaneously. Thirty two months after the third operation the infant was healthy, with no episodes of fever or jaundice.

\section{Discussion}

With an increase in the number of survivors of biliary atresia, the importance of management of postoperative complications such as cholangitis has been stressed. Percutaneous transhepatic cholangiography ${ }^{3}$ is one of the follow up diagnostic procedures which discloses some important anatomical information.

'Bile lakes' are common cyst formations seen in biliary atresia $;{ }^{4}$ they are located in the central portion of the liver and are frequently found late in the course of the disease. These cystic structures do not communicate with the intrahepatic bile ducts and probably represent dilated ductal remnants that contain inspissated secretions. ${ }^{4}$ 'Bile lakes' are usually seen at necropsy or in cases with a poor prognosis and have never been reported after successful hepatoportoenterostomy.

We have found no similar case among 155 infants with biliary atresia, of whom 38 survived. It has recently come to our attention, however, that Altman had a similar case in his series (personal communication, 1982) and we consider, therefore, that this association might be found more frequently if postoperative biliary atresia patients were followed up more carefully with repeated use of ultrasound.

These cysts may present with symptoms similar to those of ascending cholangitis. If cystic structures are found, they should be treated and percutaneous transhepatic cholangiography followed by surgical drainage may be of use.

We thank Dr R Peter Altman for the advice in the preparation of this manuscript.

\section{References}

${ }^{1}$ Kasai M, Kimura S, Asakura Y, Suzuki H, Taira Y, Ohashi E. Surgical treatment of biliary atresia. J Pediatr Surg 1968;3: 665-75.

2 Sawaguchi S, Nakajo T, Hori T. Two stage operation for congenital biliary atresia: a temporary external biliary fistula with a jejunal segment. Presented at: The 4th Annual Meeting of the Pacific Association of Pediatric Surgeons, Vancouver, Canada: 1971.

${ }^{3}$ Kimura K, Hashimoto S, Nishijima E, Muraji T, Tsugawa C, Matsumoto Y. Percutaneous transhepatic cholangiodrainage after hepatic porto-enterostomy for biliary atresia. J Pediatr Surg 1980;15:811-6.

4 Fonkalsrud EW, Arima E. Bile lakes in congenital biliary atresia. Surgery 1975;77:384-90.

Correspondence to Professor S Saito, Department of Paediatric Surgery, University of Tokyo, Tokyo, Japan.

Received 17 August 1983 